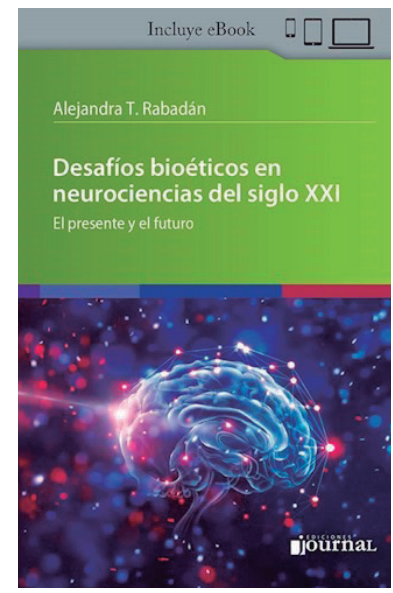

\title{
LECTURAS
}

\author{
Juan Carlos Stagnaro
}

\section{Desafíos bioéticos en neurociencias del siglo $X X I$ El presente y el futuro}

\author{
Alejandra T. Rabadán, \\ Ediciones Journal, Buenos Aires, 2022, 415 páginas.
}

Si ya es un lugar común el reconocer que la investigación básica en neurociencias y sus efectos traslacionales a la práctica médica de distintas especialidades y a otros ámbitos de la sociedad contemporánea constituye un lugar central de los intereses científicos del siglo $\mathrm{XXI}$, no es menos evidente y urgente promover una reflexión ética sobre la potencia que tales conocimientos pueden tener sobre las personas y la sociedad en general, $y$, en particular, las tensiones $y$ desafíos que le plantean a los especialistas en la toma de decisiones en el marco de su práctica.

La doctora Alejandra T. Rabadán, destacada académica neurocirujana y bioeticista, autora y compiladora de la obra, ha convocado la opinión de cuarenta y dos autores de sendos capítulos, en su mayoría de Argentina, acompañados por especialistas de Australia, Canadá, España y Estados Unidos.

Esta singular obra aborda esa problemática, tan necesaria como difícil de esclarecer, e incita a pensar sobre los dilemas bioéticos que plantean la exploración de las bases neurobiológicas de la conducta humana, las posibilidades que abre el desarrollo de nuevas tecnologías aplicadas a la medicina, la inteligencia artificial, el aumento de las capacidades cognitivas y sensoriales, el aprendizaje automático, la tele-robótica, la utilización de células madre, la evaluación de los tratamientos de algunas enfermedades del sistema nervioso y otros muchos tópicos vinculados a estos temas.

Los efectos de las neurociencias aplicadas, tanto a nivel individual como colectivo, tienen implicancias filosóficas, legales, sociales y políticas. Como lo señala la autora: "Si hay regiones cerebrales que parecen tener relaciones con algunos aspectos de la personalidad o con el modo de ser de los individuos, al igual que marcadores genéticos relacionados con determinadas tendencias, ¿es correcto medirlos? Yendo aún más lejos ¿sería legítimo utilizar determinados estu- dios antes de tomar a una persona para un empleo, antes de otorgar cargos políticos o para justificar un delito en un juicio penal?; y también podemos interrogarnos isería correcto modificarlos?". Y advierte: "Conocidos estos mecanismos por políticos, líderes de opinión o de conducción, publicistas y encargados de comercialización, podrían convertir su utilización inadecuada en manipulación”.

Además, para integrar la complejidad del campo en estudio, es necesario evitar el reduccionismo biológico comprendiendo que los condicionantes de los criterios neuroéticos no se agotan en los aspectos biológicos, sino que también se toman en cuenta los determinantes culturales y sociales, lo cual va configurando para esta nueva disciplina un enfoque antropológico.

En el campo específico de la neuroética aplicada a problemas médicos se plantea la evaluación ética de las investigaciones e intervenciones diagnósticas y terapéuticas en neuroimágenes, neuromodulación cerebral invasiva y no invasiva, psicocirugía, terapias de restauración neuronal mediante células madre, técnicas psicoterapéuticas, psicofarmacología, aprendizaje automático como tópicos de inmediato interés.

Otros aspectos esenciales en la indagación neuroética subrayados por Alejandra Rabadán son la indispensable y compleja inclusión de la opinión de los pacientes en la toma de decisiones sobre sus tratamientos, y la necesidad y posibilidades de una distribución equitativa a la población de los recursos tecnológicos de alta complejidad y los recursos humanos especializados.

En suma, un texto necesario, de vanguardia, dirigido a neurólogos, neurocirujanos, psiquiatras y a todos los profesionales del campo de las neurociencias, y también a estudiantes y profesionales de la medicina, ciencias sociales y jurídicas, y de la gestión en el área de la salud. 